\title{
Two Views of the Body in Plato's Dialogues
}

Robert Wagoner

In this paper, I identify two distinct positions on the nature of the body in Plato's dialogues. One view, which I call the pessimistic view, holds that the body is evil and as such represents an obstacle to one's epistemic and moral development. Another view, which I call the optimistic view, holds that the body is not itself either evil or good, but rather is capable of becoming either. The two views are, I argue, incompatible. Worse still, each view is individually incompatible with other claims that Plato is eager to advance in some dialogues. The pessimistic view, I argue, is (and is portrayed by Plato as being) incompatible with the thesis that one who has knowledge will not err. The optimistic view is incompatible with the thesis that no one errs willingly. Here I consider a number of passages in Plato's dialogues where the nature of the body is featured, but focus particularly on passages from the Timaeus and Laws, which explicitly endorse the pessimistic and optimistic views, respectively. Plato's views of the body, I suggest, have far reaching implications for his views on the sources of moral error and the power of knowledge in guiding right action.

\section{Introduction}

In some dialogues, Plato appears to regard the fact of our embodiment as an unfortunate one. This is clearest in the Phaedo, where Socrates characterizes philosophy itself as an activity that aims to separate the soul from the body. Doing philosophy, he claims, is nothing other than practicing for death. The view in the Phaedo is that the body contributes nothing to the soul's project of acquiring knowledge and thus of living well. Only in death, when the soul can be free of the body, can it achieve its goal. The lesson of the Phaedo (echoed with less force in other dialogues) appears to be that one should think of the body as something from which it would be best to escape. It is here in the Phaedo where Socrates likens the body to a prison (62b). Elsewhere, though, Plato seems to have a different view. In the Lysis, for example, Socrates claims that body is not in itself either good or bad (217b). This view of the body is reflected in passages that stress the proper care of the body through gymnastics and medicine. It is central, for example, to the contrast Socrates draws in the 
Gorgias between those practices, like medicine, that genuinely benefit the body and those, like pastry baking, that only seem to do so. The lesson of these passages appears to be that there is a proper way of thinking about and caring for the body which one would be hardpressed to characterize as a form of 'escape' from it. These two ways of thinking about the body appear to be at odds. They appear, moreover, to support different answers to questions about the status of the body about how we should treat the body.

The passages noted above give some indication of the two ways of thinking about the body. For the sake of convenience, I will refer to the two views as the optimistic view (or optimism), according to which the body is neither good nor bad in itself, and the pessimistic view (or pessimisim), according to which the body is somehow associated directly with evil. I take it that most readers of the dialogues will be familiar with these different attitudes toward the body. I suggest here that these are not differences that can be understood as consistent with each other. I argue that Plato's claims about the body are connected - as premises or assumptions - to conclusions he draws about other matters. In particular, the nature of the body figures importantly in Plato's discussions of the nature and origin of evil. The connection between the body and evil, in turn, figures into his discussions of the origin of human error and the role that knowledge plays in overcoming error. Though I do not here argue that Plato ultimately chooses either the pessimistic or optimistic view, I argue that the choice between the two represents a dilemma for Plato. I argue that costs of each horn of the dilemma are on full display in two dialogues - the Timaeus and Laws - where the pessimistic and optimistic views are explicitly adopted. While much attention has been given to Plato's moral psychology, comparatively little has been said about the extent to which the body exerts influence on the soul's powers of reasoning, yet the passages that I propose to explore here demonstrate that sorting out the status of the body is, or at least becomes, a somewhat pressing concern for Plato.

\section{The Body and Evil}

Plato emphasizes in a number of dialogues that the body is an obstacle to either knowledge or virtue (or both). The body is described - sometimes explicitly, sometimes 
implicitly - either as a positive evil or the cause of evil. ${ }^{1}$ Thus, in the Phaedo, Plato likens the body to a prison (62b). In the Phaedrus, the body is the shell that the soul must drag around (250c). In the Gorgias, Socrates reports the view of wise men that the body is actually a tomb (493a). Metaphor aside, Plato sometimes describes the body as positively evil. In the Phaedo, Socrates claims that, "as long as we have a body and our soul is fused with such an

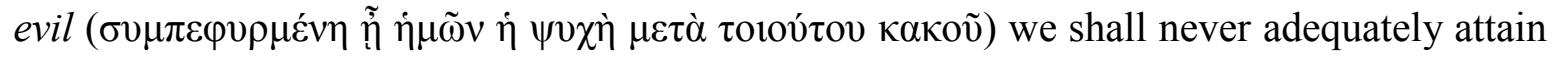
what we desire, which we affirm to be the truth" (66b). ${ }^{2}$ Later in the Phaedo, and again in the context of a discussion of the body's role in acquiring knowledge, Socrates claims that the soul "is dragged by the body to the things that are never the same, and the soul itself strays and is confused and dizzy, as if it were drunk, in so far as it is in contact with that kind of thing" (79c). ${ }^{3}$

One would be hard-pressed to deny the pessimism about the body in these passages. The message in these passages is clearly that the body is evil in itself. As such it is capable of causing further evil (epistemic or moral error) in an embodied soul. Whether the body is understood as a shell or tomb or prison, or, whether it is conceived as frustrating the soul's attempt to gain understanding, the body is seen as inevitably getting in the way. Indeed, the pessimistic view of the body leads to a further pessimism about the embodied person's chances at gaining knowledge. Socrates claims that it seems that "either it's never possible

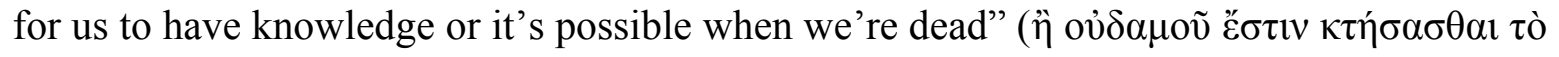

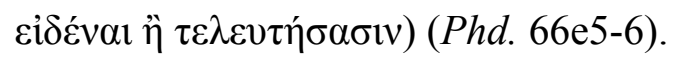

${ }^{1}$ Plato's understanding of the nature and origin of evil has long been a matter of scholarly attention. Harold Cherniss (1954, p. 23. n.1) cites over a dozen parties to the debate about Plato's conception(s) of the sources of evil in the dialogues. As Cherniss notes, the options seem to be roughly one of the following: (1) Plato's view is that evil is ultimately explained by the corporeality of the physical world; (2) Plato's view is that evil is ultimately explained by irrational elements in the human soul; (3) Plato does not have one single coherent view about the ultimate cause of evil. There is similar uncertainty about the nature of evil in the dialogues. Evil may be understood as (1) a departure from or derogation of reality (e.g., individual substances as imperfect instantiations of the Forms), or as (2) some kind of disunity or disharmony in the organization of some complex, or (3) the deliberate choice by an agent to do what fails to be good. Writing more recently, James Wood notes that on these and related difficulties, no consensus has been reached $(2009,349)$. I make no claim to answer any of these questions but rely minimally on the claims that (i) human error (epistemic and moral) counts as evil, and (ii) disorder, whether in the cosmos generally or in individuals, is evil.

${ }^{2}$ Translations from the Phaedo are from Grube, in Cooper, 1997.

${ }^{3} \mathrm{Cf}$. also Prot. $326 \mathrm{~b}$. Protagoras notes that sound bodies serve sound minds, while bodily deficiencies

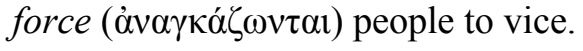


The epistemic constraints placed on us by the body are a recurring theme in contexts where the pessimistic view is featured. This is clearest in the Phaedo, but is evident elsewhere as well. The discussion in the Phaedrus leading up to the shell passage points out that those souls who were able to attain a glimpse of the Forms were able to do so because they were

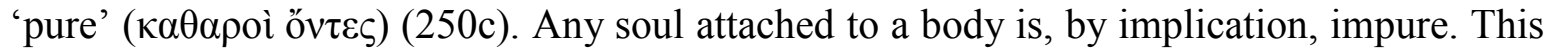
language occurs in the Phaedo as well. Socrates claims that we must strive to 'purify' ( $\alpha \theta \alpha \rho \varepsilon v ́ \omega \mu \varepsilon v)$ ourselves from our body as much as possible while we are alive (67a). ${ }^{4}$

So much, then, for now, about the pessimistic view. The optimistic view appears in number of familiar dialogues. The most explicit expression appears in the Lysis where Socrates notes, while discussing the benefits of medicine and the badness of disease, that,

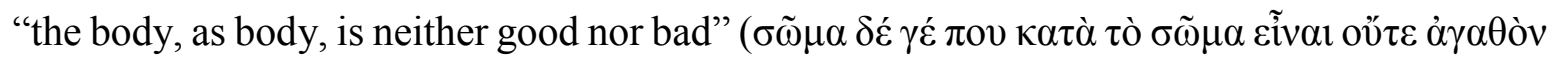

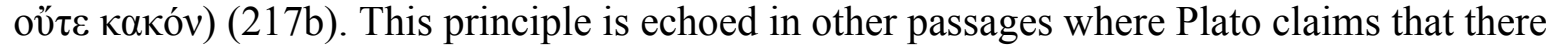
are both good and bad bodily conditions, and that there are proper forms of bodily care. ${ }^{5}$ Consonant with this line of thinking about the body are Plato's claims about bad bodily conditions, especially disorder. At one end of the spectrum, Plato seems to think that a body that is disorderly or disorganized beyond hope can destroy one's life, ${ }^{6}$ while at other the end, Plato notes that a wise person will be able to endure the sight of a body that lacks harmony. ${ }^{7}$ In these contexts, and in keeping with the optimistic view, the notion of evil that seems to be at work is typically that of disorder or disharmony. On this way of thinking, neither a body nor a soul nor anything else can be said to be evil in itself. No inherent disorder or evil under some other description is attributed to the body. Whether something counts as evil can only be determined by looking to its order. ${ }^{8}$

Thinking of the status of the body in terms of the optimistic view seems to fit well when the concern is with achieving or maintaining order. The emphasis in the Republic on

${ }^{4} \mathrm{cf}$. Phd. $82 \mathrm{~b}$ ff.

${ }^{5}$ Cf. Alcibiades I 126a \& 128c ff.; Hippias Major 295c; Gorgias 517a ff.

${ }^{6}$ Cf. Gorgias, 505a.

${ }^{7}$ Rep. 402d.

${ }^{8}$ In this way, the general discussion of the Republic about the best and worst constitutions is relevant to the account of evil. What makes the aristocratic constitution of Book 4 superior to the other constitutions in the later books is primarily that the former is well-ordered and unified, while the latter are to varying degrees badly ordered. 
education in music and poetry makes sense if this is taken to be the view about the body. Such a regimen is advisable only if such training can produce a body that is well ordered. The optimistic view also appears to underpin discussions of the proper care of the body elsewhere. Socrates' discussion of oratory, sophistry and so on in the Gorgias begins from thinking about good and bad ways to treat a body. ${ }^{9}$ Whereas pastry baking and cosmetics do nothing to improve the condition of a body, gymnastics and medicine are directed at maintaining and producing sound bodies. On the pessimistic view, this would make little sense, as bodies in whatever condition are evil in themselves. The language of 'purification' suggests minimizing engagement with the body rather than attending to its needs. On the optimistic view, however, the effectiveness of medicine and gymnastics is explained by the body's being neither good nor evil in itself and by the need to produce and maintain proper order in it.

The passages considered so far show that Plato's thinking about the body is closely connected to his thinking about evil itself. In contexts where pessimism dominates, the associated account of the nature of evil itself is often opaque. The clear message from the Phaedo is that the body is evil and its being so explains the role it plays in causing error. In contexts where the optimistic view appears, however, there is typically a clearer account of the nature of evil. There the arguments rely on an account of goodness as involving order, unity, or harmony. Evil, in these contexts, is typically understood as some kind of disorder. While it is conceivable that these ways of thinking about evil are compatible - i.e., that the body causes evil and the evil that it causes is disorder - the two notions are not typically together in the dialogues. ${ }^{10}$ There are, perhaps, some reasons for keeping these notions separate. If the body is taken to be evil (qua disorder), then arguments that stress the good condition of the body (achieved through medicine and the like) are threatened. On the other hand, if the body is not taken to be evil (qua disorder) in itself, then we would need a further account of the cause (or causes) of disorder.

These two views about the body then, appear to correspond to distinct questions about evil. The pessimistic view gives a relatively clear answer to the question about the ultimate

\footnotetext{
${ }^{9}$ Gorgias $462 \mathrm{a} \& 465 \mathrm{c}$.

10 The exception, as I argue below, is the Timaeus.
} 
origin of evil - namely, that it originates in the body. The optimistic view, on the other hand, appears to correspond to an answer to the question about the nature of evil - namely, that it is disorder, disunity, or lack of harmony. Neither way of understanding the body, however, seems to answer both questions. The pessimistic view tells us nothing about the nature of evil. The optimistic view leaves the origin of evil mysterious.

\section{Error and Action}

The fact that each of these views finds support in the dialogues suggests that Plato's thinking about the status of the body and its relation to evil is not well developed in the dialogues. Plato appears to give different accounts of the body in different contexts, and his thinking about the body seems to be guided more by the demands of a particular context than by a firm view. Indeed, none of the dialogues mentioned above contain a sustained discussion of the nature of the body, despite Plato's insistence that an account of just this is needed in order to say just what qualities make bodies good or bad and to show just how one ought to care for a body. ${ }^{11}$ Perhaps it is not so difficult to understand Plato's inattention to these matters. Consider Socrates' claim that he serves the god and benefits the city by doing

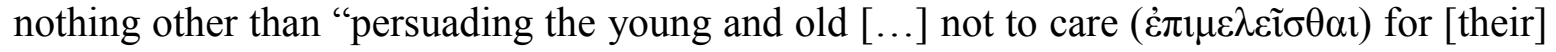
body or wealth in preference to or as strongly as for the best possible state of the soul" ( $\mathrm{Ap}$. 30a). In other words, whether the body is itself inherently evil in some sense and therefore the cause of other evils, or whether the body is neither inherently good nor evil, are questions that Socrates deems less important than questions about virtue. Whichever view of the body holds true, the important point is that one should devote one's attention to the cultivation of virtue.

${ }^{11}$ Cf. Clitophon 410d: "I mean, if it had been about gymnastics that you were exhorting me, saying that I must not neglect my body, you would have proceeded to give me what comes next after such an exhortation, namely, an explanation of the nature of my body and of the particular kind of treatment this nature requires..." (Gonzalez, F., trans.) \& Hip. Maj. 295c: In evaluating whether a thing is fine or not, first "we look at the nature it's got, its manufacture, its condition..." (Woodruff, P., trans.). While these passages focus on the body, the general point that it is important, in advance of saying whether something is of a certain quality, to give an account of the thing's nature is one that Socrates insists upon throughout the Socratic dialogues. 
While Plato never seems to abandon the claim that one should care more for the soul than the body, the differences between the two views suggest different answers to questions about just how one should care for the body. Plato's attention to these, especially in the Timaeus and Laws, suggests that some care, in the form of understanding the nature of the body, is indeed needed. ${ }^{12}$ We have seen already how the choice between optimism and pessimism is related to Plato's thinking about evil. That discussion must remain partly speculative just because Plato does not develop a clear account of evil. Here, though, I turn to two claims to which Plato is more explicitly committed. The connection between these claims and a choice between optimism and pessimism is clearer. I begin here by sketching these two claims and indicating how they appear to relate to the two views. In the following sections, I argue that these connections are made more explicit in the Timaeus and Laws.

The first is Plato's defense of the thesis that no one errs willingly. Plato's defense of this thesis has long been a matter of controversy. ${ }^{13}$ Whether it is successful is secondary here to questions about the source of error. If error is not to be explained by an act of will, then to what does Plato appeal to explain widespread human error? The ready answer in both the Protagoras and Gorgias, the loci classici for this thesis, is simply: ignorance. The many, in the Protagoras, and the tyrant, in the Gorgias, err because they fail to have knowledge. In the Gorgias, the tyrant and orator err - they fail to do what they want - because they have mistaken beliefs about what is really good. ${ }^{14}$ In the Protagoras, the error of the many is explained by ignorance of a specific kind. Those who err do so because they rely on the

${ }^{12}$ I neither intend nor defend here any substantive claim about the difference between Socrates and Plato. It is noteworthy, it seems, that the two dialogues (Timaeus and Laws X) where I find Plato most engaged with the question about the body's nature and its relation to evil are dialogues where Socrates is either largely or entirely absent. Beyond this observation I have no argument. My claim is that Plato's claim about the body at Apology 30a, given in the voice of Socrates, is one that he returns to in these dialogues. If 'caring' includes 'knowing about', then these dialogues take a different stance. Whether this is Plato disagreeing with Socrates or Plato changing his mind or Plato developing an inchoate idea or something else is beyond the scope of this paper. The optimistic view and the pessimistic view are, as I see it, incompatible views. Worse still, they are both incompatible with other views Plato holds. My main aim here is to trace Plato's attention to this in the dialogues.

${ }^{13}$ Cf. Segvic (2000) \& MacKenzie (1981).

${ }^{14}$ Cf. G. 455a, 465a, 468b-e. 
power of appearance rather than the art of measurement. ${ }^{15}$ No one who knows - that is, who possesses the art of measurement - would mistake a lesser pleasure for a greater one.

In one way, Plato's appeal to ignorance as the explanation of error is satisfactory. It highlights the value of knowledge in leading a good life, and fits with Plato's conception of knowledge and virtue. The latter is understood as analogous to practical skill, the acquisition of which requires both intellectual and non-intellectual training, all of which is difficult. Thus, identifying ignorance as the cause of error fits well with his broader ethical commitments, but it leaves unanswered a question about the ultimate origin of error. Though this can be construed as a wide reaching metaphysical problem (and it is treated as such below in the discussions of the Timaeus and Laws), a narrower version of the question recurs in the dialogues. Consider, for example, Socrates' challenge to Protagoras' claim that virtue can be taught. ${ }^{16}$ Here, Socrates appeals to the widely recognized phenomenon that good parents often fail to have good children. If those in the care of Pericles fail to avoid ignorance, how could anyone? Ignorance seems to be a persistent feature of the human condition. Given its persistence, it would seem reasonable to ask what Plato takes the original cause of ignorance to be.

Though Plato's attention to ignorance as such is limited in the dialogues, his discussions of it generally take one of two directions. On the one hand, ignorance is discussed as a state of the soul that is contrasted with knowledge. Those who have knowledge do well in various ways or live well, while those who are ignorant do badly or live badly. Though discussions of this kind do not address the question of the ultimate origin of ignorance directly, I suggest that they often rest on the assumption that the body is the cause of ignorance. Consider, for example, the distinction between those who are led by the power of appearance and those who are led by the art of measurement. The former are led astray just because they rely too heavily on the senses. On the other hand, some discussions particularly those noted above in connection with the pessimistic view - straightforwardly attribute ignorance to the body's interference with the soul's operations.

\footnotetext{
${ }^{15}$ Cf. Prot. 357b-e.

${ }^{16}$ Prot. 319a ff.
} 
A second claim that seems to be affected by Plato's account of the nature of the body is the claim that knowledge, when present, overrides all other motivational factors. This is closely related to the thesis that no one errs willingly. We might call this the thesis the infallibility thesis, as it holds that no one who has knowledge errs. While this is, like the thesis that no one errs willingly, a controversial Socratic claim, it is clear that Plato is committed to its truth in a number of dialogues. ${ }^{17}$ While the connection between this thesis and Plato's thinking about the body is not obvious from the dialogues, it is helpful to think of the infallibility thesis as setting a theoretical constraint on any account of evil or error that may be put forward. Whatever causes human error cannot be so powerful as to disrupt the infallibility of knowledge in guiding action.

Considered independently of other claims, the thesis that no one errs willingly and the infallibility thesis are consistent. They are complementary claims - one about the authority of knowledge in motivating action and one providing an analysis of motivations in cases where knowledge is absent. It is also apparent that the claims are taken to be mutually supportive. In the Protagoras, for example, the argument designed to show the error of the many in supposing that knowledge is not powerful relies on the assumption (undefended in that dialogue) that one with knowledge would not err. Again, in the Gorgias, Socrates' discussion with Polus aims to show that everyone truly wants what is good (and so only errs unwillingly) by pointing to the fact that one who has knowledge does not make mistakes. Despite these relations of support, matters are complicated when these theses are coupled with either the pessimistic or optimistic views about the body. In the following sections, I focus on the Timaeus and Laws, where Plato explicitly adopts the pessimistic and optimistic views (respectively). These dialogues show that explicitly adopting one or the other view leads to the rejection of at least one of the two theses considered in this section.

${ }^{17}$ Cf. G. 460b-d, Rep. I 340e ff. 


\section{Pessimism in the Timaeus}

While the interpretation of the Timaeus is rife with difficulties, two features of the dialogue are important here. ${ }^{18}$ First, whatever else Plato may aim to achieve in the Timaeus, it is clearly his most ambitious attempt at sorting out the relation between the body and the soul. This is true both at the level of the human being, where Timaeus painstakingly details the workings of the human body and its interactions with the soul, and at the cosmic level, where he details the relation between the workings of the rational soul and the facts about the material constituents of the cosmos. Timaeus' concern to account for the structure of the cosmos requires that he give a clearer account of the nature and status of the body than those Plato has given in other dialogues. The second feature of the Timaeus that distinguishes it from the dialogues considered so far concerns the context of the discussion of the body. Whereas in those dialogues the body enters into the discussion as the explanation of error or evil (where the pessimistic view is prominent) or as an example of the need for promoting order and health (where the optimistic view is prominent), the discussion in the Timaeus is, at least at a very general level, more metaphysical than epistemic or ethical. The body, and bodily entities generally, are part of the explanation Timaeus gives for the world's being as it is.

18 Three central interpretive questions about the Timaeus are (1) whether Timaeus' creation story should be taken literally or metaphorically, (2) how, or when, the Timaeus fits with other, especially later, dialogues, and (3) how to understand Timaeus' repeated references (e.g., at 28d, 30b) to his account as an eikôs mythos or eikôs logos. Each question has received a great deal of attention in some cases since the generation after Plato's writing. For (1) and (2), see Zeyl (2000, x-xv \& xvi-xx, respectively) for an overview of the literature. For (3), see Johansen (2004, Ch. 3). My reading of the dialogue here offers little to either side of these three debates. With respect to (1), my reading takes the account at face value (i.e., literally) but does not require that Plato is committed to the letter of the story Timaeus gives. My interest is in showing what follows from a certain assumption - i.e., the pessimistic view - about the nature of the body. With respect to (2), my reading assumes, weakly, only that the Timaeus is later than the Phaedo. While I take this to be uncontroversial, it is not an essential assumption of my argument. While I assume that part of what Plato does in the Timaeus is to provide an account of the sort Socrates' wishes for in the Phaedo, this story is not essential. It could just as well be the case that Plato articulates, in the Phaedo, what he has carried out in the Timaeus. With respect to (3), I take Timaeus' proviso, together with his repeated reminders, that he is delivering a likely account to be good evidence of Plato's distance from the variety of specific claims. At the very least, such hedging suggests that the view that appears in the dialogue may need further development. If what I have to say about the consequences of the pessimistic view as they unfold in the dialogue is correct, then I will have identified one matter that cries out for such further development. 
The premise of the cosmological account in the dialogue is that the Demiurge wanted

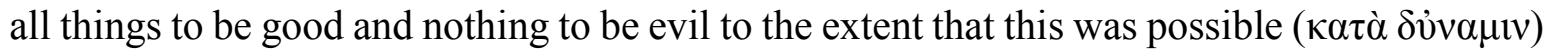
(30a). Timaeus acknowledges that some evil in the cosmos is inevitable, given the material from which its visible portion is crafted. The activity of the Demiurge is such that it brings goodness, understood in terms of order and harmony, to an otherwise disordered pre-cosmic material. In bringing the material of the cosmos into its present form, the Demiurge first has to curtail, again as much as possible (53b), the tendency of the material constituent toward

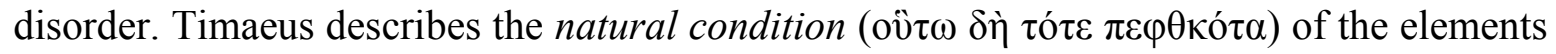
as the condition one would expect "thoroughly god-forsaken things to be in" (53b). ${ }^{19}$

The evil at the cosmic level is closely connected to the imperfection of the material constituents of the world. While some have regarded this kind of evil as a kind of 'negative' evil, the text suggests something stronger. It is not just that the material cosmos is evil in falling short of the ideal after which it is modeled. The material constituents are described as having natural features that set limits on the Demiurge's activity. Indeed, there are very specific ways in which the material of the cosmos frustrates the Demiurge's efforts. Chief among these is the tendency of the material toward disorder. Timaeus' repetitive hedging about the Demiurge's effort to bring the material of the cosmos into order "as much as possible" suggests that evil lurks in the cosmos despite the causal power of noûs in ordering it and that the evil is located in the material constituent. ${ }^{20}$

The body's influence on the human soul, first described at 43a-b, is more pronounced. Timaeus notes that the effect of the body on the soul, the primary operations of which are the movements of the circles of the same and the different, is such that the circles become mutilated and disfigured (43e). The passage from 43a to 44a is reminiscent of the Phaedo's discussion of the ill effects of the body on the soul's ability to know the world (63e-7d). While the Phaedo gives an image of the body as a prison for the soul and observes how the body can frustrate the soul's attempt to gain knowledge, the account says little about how the body is able to affect the soul. The account in the Timaeus, on the other hand, gives a much richer picture of how the body affects the soul - particularly at the moment of embodiment.

\footnotetext{
${ }^{19}$ Zehl trans.; cf. also 69b.

${ }^{20}$ Tim. 30a, 53b, 69b.
} 
Only with proper nurture and education can the soul turn out to be perfectly healthy (44bc). The suggestion in this passage is that the body plays an important role in the epistemic development of the soul.

This suggestion is confirmed in a passage later in the Timaeus. At 86b, Timaeus discusses the body's role in producing diseases in the soul: Kaì $\tau \grave{\alpha} \mu \varepsilon \grave{\varepsilon} v \pi \varepsilon \rho \grave{~} \tau$ ò $\sigma \tilde{\omega} \mu \alpha$

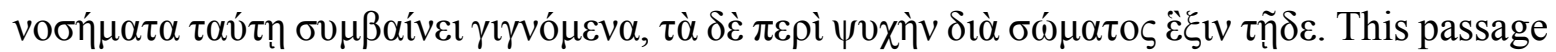
is susceptible to two distinct interpretations (and translations). According to the weaker reading of the passage, the sentence should be translated thus: "The foregoing described how diseases of the body happen to come about. The diseases of the soul that result from a bodily condition come about in the following way." ${ }^{21}$ The stronger reading of the passage holds that the second clause reads "The diseases of the soul come about from the body in the following way." 22 Whether one accepts the weaker or the stronger reading, the passage makes clear that on either all (on the strong reading) or at least some (on the weak reading) occasions, diseases of the soul (madness or ignorance) are caused by the body in such a way that the soul is (at least at the moment) powerless to stop. The badness of the body overpowers the soul, whatever the soul's quality. This is a difficult and controversial passage, ${ }^{23}$ but the context makes it clear that this claim is to be taken as an explanation of the common error that people make in blaming wrongdoers for their actions. The truth is that "no one is willfully evil"

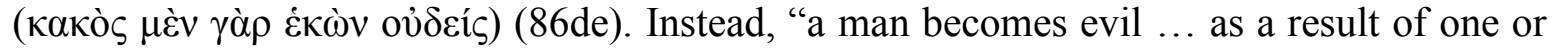

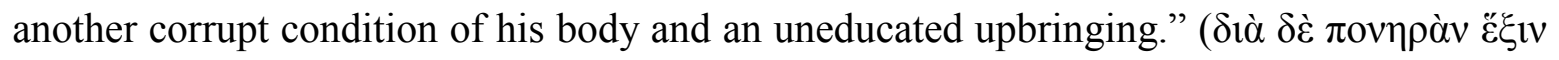

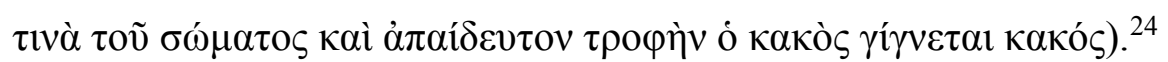

This passage suggests that evil (in the form of human error or wrongdoing) is caused and explained by the body. Even on the weak reading, the body is a sufficient cause of error. The implications of this position have been obvious to readers of the dialogue, though many have, as Andrea Nightingale notes, been "loathe to ascribe to Plato such a deterministic

${ }^{21}$ Zehl, trans.

${ }^{22}$ Cf. Gill, 2000, 60 ff.

${ }^{23}$ For a survey of the cases for and against both the weak and strong readings of the passage, see Gill, 2000.

${ }^{24}$ Zehl, trans. 
doctrine". ${ }^{25}$ Nightingale notes that Plato quickly backs off this position in the following passage, where Timaeus exhorts his audience to strive as much as possible to escape vice. ${ }^{26}$ My view is that despite what else he says here, the deterministic doctrine is a logical consequence of the pessimistic view of the body. ${ }^{27}$ The Timaeus is, after all, a dialogue in which the speaker aims to explain the causes of the world's being as it is. The main point of that account, reminiscent of Socrates' hopes in the Phaedo, is to show how the world is organized by noûs, but the full account requires that the workings of necessity (including the causal influence of the material constituent of the cosmos) be given in full. It follows from this account that either all or some moral and intellectual error is the direct result of the body.

Two things, in turn, seem to follow from this. First, the Timaeus account of the body is one that is consistent with the thesis that no one errs willingly. This is stated explicitly at $86 \mathrm{~d}$. Second, it is an account according to which error may occur in such a way that reason, wish, deliberation, or any other psychic movements are completely undermined or overruled by the body. In other words, the infallibility thesis is ruled out by the pessimistic view.

While the first of these implications is a welcome one, the second is one that Plato is otherwise eager to deny. While it is still possible, on the account given here, to explain one's failure to act correctly in ways that align with the thesis that no one errs willingly, the Timaeus

${ }^{25}$ Nightingale, 1996, 67.

${ }^{26}$ Nightingale, 1996, $67 \mathrm{ff}$.

${ }^{27}$ Nightingale notes two passages that seem to count against the deterministic reading. First, as noted above, Plato claims at $87 \mathrm{~b}$ that one should strive for virtue and try to escape vice through nurture and one's learning. Second, Nightingale points to a passage at Tim. 42b. Here, in his discussion of the emotions that arise in the soul as the result of embodiment - fear, pleasure, pain, and so on - Timaeus notes that "if they should conquer these [sc. emotions], they would live justly, but if they should be conquered, unjustly" (Nightingale, trans.). Nightingale concedes that the call for striving for virtue is 'a bit lame' but takes the passage at $42 \mathrm{~b}$ to show that the soul has the capacity to overcome the influence of the body (68). It is not clear to me that the passage at $42 \mathrm{~b}$ is relevant to the passage at 86b. From 41e-42d, Timaeus recounts the Demiurge's explanation of the ordinances of the cosmos to un-embodied human souls. But whether the soul, once embodied, has the capacity (or sufficient capacity) to overcome the body is not something over which the Demiurge seems to have control. The creation of human bodies is handed over to the lesser gods in order that the Demiurge may not be responsible for any evil they create (42d). It is on this matter that Nightingale finds fault in the account. Given that the Demiurge created the souls, and given that so few (perhaps none) seem adequate to conquer the emotions caused by embodiment, it is unclear whether the account succeeds in recusing the Demiurge of responsibility. Whether it does so or not, the actual creation of human bodies is left to the lesser gods. One outcome of their work is that souls are susceptible to the influence of the body. The passage at $86 \mathrm{~b}$ ff. suggests that this influence is quite strong - perhaps stronger than the Demiurge would have hoped. 
account appears to allow for cases where someone's being in possession of the knowledge of what is best may not be sufficient to guarantee correct action. If the body is the cause of error, then according to the account developed in the Timaeus it is (at the very least in some cases) a cause of error that cannot be overcome by knowledge. ${ }^{28,29}$ Thus the pessimistic view of the body, considered in full in the Timaeus, turns out to be too strong. It succeeds in upholding the thesis that no one errs willingly but undermines the conception of nôेs as an infallible guide to right action that is at the core of that thesis.

The denial of the infallibility thesis is in one way a theme of Timaeus' account. His repeated claims that the Demiurge sought to bring the material of the cosmos into order as much as possible and his insistence that a full account of the cosmos must include a full accounting of the non-rational causes - especially necessity - of its being as it is serve to highlight that knowledge, even in the hands of the divine craftsman, may fail to achieve perfect outcomes. Presumably, the work of the divine craftsman will be, as Timaeus claims, as good as possible; but the outcomes of imperfect human beings, even those who possess knowledge, may well fail to be good, despite their knowledge and desire for good outcomes. I suggested above that Plato is in a bit of a bind when it comes to his thinking about the body and its relation to evil. The body cannot, it seems, both be evil in itself and at the same time be susceptible to goodness (via its having or achieving order, harmony, or health). On the other hand, if the body is not evil in itself and is thus susceptible to goodness, then a new and different story is needed both about the actual origin of evil (and error) and about the role of the care of the body in the good life. I suggest that a different, though perhaps related, bind arises in connection with the role of the body in causing evil and the role that knowledge plays (or is thought to play) in producing right action. The body's being the cause of evil appears to undermine the claim that knowledge, when present, produces right action. On the

${ }^{28}$ Although the passage at 86de suggests that a person's becoming evil requires both a corrupt condition of the body and an uneducated upbringing, the conjunction of these two is not well defended in the dialogue. No account is given of how having a good education - or even having knowledge would enable one to prevent in every case the kinds of transformations of the body that lead to the diseases of the soul. Timaeus claims that one ought to make every effort to escape vice, but stops short of saying how doing so would help, claiming that this is the topic 'for another speech' (87b).

${ }^{29}$ It is perhaps helpful here to recall Timaeus' claim (86b) that the disease of the soul - mindlessness $(\not \alpha v o l \alpha)$ - comes in two forms: ignorance $(\dot{\alpha} \mu \alpha \theta \dot{\alpha} \alpha)$ and madness ( $\left.\mu \alpha v^{\prime} \alpha\right)$. While there is something paradoxical in the claim that knowledge cannot overcome ignorance, the claim that knowledge cannot overcome madness is perhaps more palatable. 
other hand, if knowledge is sufficient to overcome the influence of the body, then either a new and different account is needed of the body which makes a better case for how knowledge can overcome its influence or a new account of the origin of evil is needed. The Laws appears to take on both of these. In adopting the optimistic view of the body, the Laws denies the thesis that the body is evil in itself. In Laws X, moreover, a different account of the origin of evil is defended.

\section{Optimism in the Laws}

Like the Timaeus, Laws X offers a teleological account of the cosmos. While the Timaeus presents the account as a didactic speech, the Laws $\mathrm{X}$ account appears in the form of an argument designed to persuade the citizens of Magnesia of the truth of three distinct doctrines - that the gods exist, that the gods are concerned for human affairs, and that the gods cannot be bribed. Parts of this argument will be the primary focus here but it should be noted beforehand that discussion of the role of the body is largely absent in the arguments of Laws X. Indeed, the argument partly turns on denying the thesis that the bodily constituent of the cosmos plays a causal role in its being as it is.

Despite the absence of discussion of the body in Laws X, discussions of the nature of the body and, in particular, the proper attitude toward it, abound in the Laws generally. These discussions show that that Plato has abandoned the pessimistic view in this dialogue. Thus, some preliminary remarks regarding the Laws' treatment of the role of body are warranted. First, there is great concern in the Laws for producing citizens whose bodies are balanced and orderly. The cultivation of the body in Magnesia must begin very early in the lives of citizens. The Athenian recommends, though he is hesitant to legislate, that pregnant Magnesians go for regular walks, and that nurses regularly carry small children around in order that proper digestion, balance in the body, and strength are promoted (789ce). Young citizens are to be participants in certain kinds of wrestling, choral dances, and military exercises all aimed at producing strength and health (796ad). ${ }^{30}$ Second, there is a concern in the Laws that things be honored appropriately. Repeatedly, the Athenian points out that soul

\footnotetext{
30 Just how participating in such exercises is thought to promote virtue is a matter of controversy, given the moral psychology of the dialogue. Cf. Kamtekar (2010) and Bobonich (2002).
} 
is to be honored above and before body. ${ }^{31}$ The message in these passages is not that the body is evil or the origin of evil, but rather that one must not honor the body more than the soul (or the divine). The body is, nonetheless, something to be honored.

The Athenian elaborates on this in a passage at $728 \mathrm{de}$. Having established that the body has the third rank of honor (after the gods and the soul), the Athenian gives the following account of what kind of body is correctly honored and why:

The body that deserves to be honored is not the handsome one or the strong or the swift - nor yet the healthy (though a good many people would think it was; and it is certainly not the one with the opposite qualities to all these. He [i.e., the legislator] will say that the body which achieves a mean between all these extreme conditions is by far the soundest and best-balanced, because the one extreme makes the soul bold and boastful, while the other makes it abject and groveling. ${ }^{32}$

This passage makes a point familiar from other dialogues - namely that the condition of the body can affect the soul. This way of understanding the body echoes the passages from those dialogues where the optimistic view is prominent, but here Plato has expanded the account to make it clear how one ought to regard the body. To say that the soundest and bestbalanced body is the one neither excessive nor deficient in being handsome, strong and swift (and healthy!) emphasizes two points that the Athenian is pressing in this passage. First, the body, which attains the third place of honor, should not be excessively honored. Whatever honor swiftness and strength deserve, it does not surpass that owed to the gods and the soul. This is related to the second concern - that excessive attention to physical prowess could lead to or require failure to honor the soul or the gods. This point is reinforced in a subsequent passage. The Athenian notes that the same point holds for money and other goods. An excessive amount of these things gives rise to feuds and enmity among citizens, while too little of them leads to slavery (728e). The point here is that honoring bodily excellences is disruptive and can lead to failure to properly honor the soul.

In general, then, the Laws conforms to the optimistic view. The body is neither good nor evil in itself but can become either. Thus, a great deal of attention is needed for cultivating bodies that are in a good condition. It appears, as well, that here Plato aims to uphold Socrates' dictum (Ap. 30a) that more care should be given to one's soul than to one's body,

${ }^{31}$ Cf. Laws III 697b; V 726 ff.; V 743de.

${ }^{32}$ Laws. V 728de. Unless otherwise indicated, translations from the Laws are from Saunders, in Cooper, 1997. 
while still maintaining that the body cannot simply be neglected. All of this suggests that in this dialogue Plato is proceeding with a different view about the origin of evil. This will be confirmed in Laws X when the Athenian posits the existence of an evil soul.

\section{Laws X and the Evil Soul}

Two elements of the arguments in Laws X are relevant to the account of evil that emerges in this text. First is the claim that soul is prior to body. Second is the account of human agency that is sketched as part of the argument that the gods - as distributors of cosmic justice - are concerned with human beings. I am interested here in two implications of these claims. The first claim requires the rejection of the pessimistic view. The second element entails, I hope to show, the rejection of the thesis that no one errs willingly. Only by acknowledging that human agents are capable of willful wrongdoing can Plato preserve the intuition that knowledge in the hands of those who do wish to do well is infallible. The arguments in Laws X show that the assertion that no one errs willingly, relying as it does on the pessimistic view of the body, gives too much to the materialistic view of the cosmos. That view is the topic of sustained critical attention in Laws X.

The Athenian's first task in Laws X is to provide an argument that the gods exist. The opponent - an imagined materialist - claims that the arrangement of the cosmos is the result of "nature and chance" (889ae). According to the materialist, the elements (or perhaps atoms) that constitute the material of the cosmos are, by their combinations and dissolutions, responsible for the ordering of the heavens, the seasons, the regularities of animal and plant life. On this view, "the cause of all this...was neither intelligent planning, nor a deity, nor

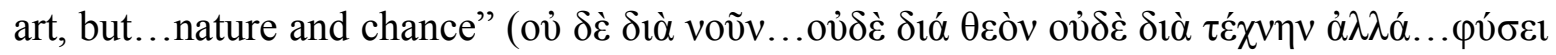

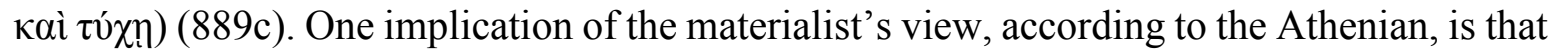
soul comes to be later than (and as the result of the combination of) the material elements. On this materialist account, the soul, along with its capacities, is not preeminently 'natural'. The natural elements of the cosmos are the material elements - fire, water, etc. The Athenian's response is to argue that the materialists are mistaken on just this point. It is, he argues, soul that is prior to body rather than the other way around. The defense of this claim is the first part of the positive argument for the existence of god. 
It is not my concern to evaluate this argument. Instead, I want to emphasize certain of its results that are relevant to the account of evil. Four features of the account of soul that is developed from 892 a to $897 \mathrm{~d}$ are relevant. First, soul is defined at $896 \mathrm{a}$ as a "self-moving mover" ( an external mover (895b). Second, since soul is "the original cause of the generation and motion of all past, present, and future things and their contraries" (

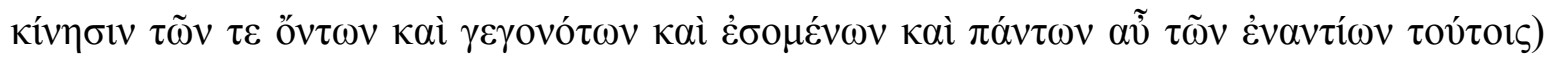
(896a), and since the soul is prior to matter (896bc), soul is also a fortiori the "cause of good and evil, beauty and ugliness, justice and injustice and all the opposites" ( $\tau \tilde{\omega} v \tau \varepsilon \dot{\alpha} \gamma \alpha \theta \tilde{\omega} v$

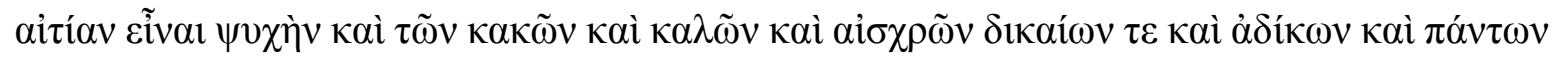
$\tau \tilde{\omega} v \dot{\varepsilon} v \alpha v \tau i ́ \omega v)$ (896d). Third, there is more than one soul - "that which does good, and that

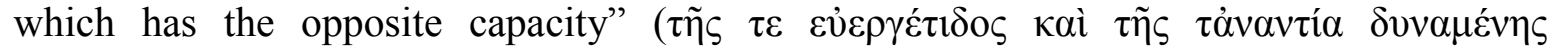
$\dot{\varepsilon} \xi \varepsilon \rho \gamma \alpha \dot{\zeta} \varepsilon \sigma \theta \alpha 1)$ (896e). The Athenian later refers to the second as the "evil soul” ( (897d). Finally, when soul "cleaves to (divine) reason" ( voṽ $\mu \varepsilon \grave{\varepsilon} v \pi \rho \circ \sigma \lambda \alpha \beta o \tilde{\sigma} \sigma \alpha)$ " and orders things appropriately it is $\operatorname{good}^{33}$, and when it "allies itself with unreason and produces

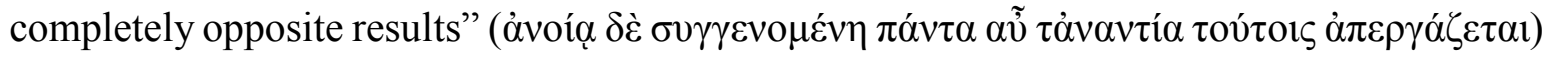
it is evil (897ab).

These claims about soul make it clear that the origin of evil in the cosmos is the soul. The body cannot be an original cause of evil - or of anything - in the soul since body is secondary to soul. ${ }^{34}$ The claim that both good and evil (along with many other contrarieties) are caused by soul arises dialectically as part of the Athenian's attack on the atheist's materialism, but once established, it guides his account in much the way that Timaeus' claim that the body is the cause of evil guided his account.

If the soul is the ultimate cause of evil, it does not immediately follow that the no one errs willingly thesis is to be affirmed or rejected. Similarly, it is not obvious what, if any, implication the claim that evil is caused by soul has for the infallibility thesis. The Athenian's

${ }^{33}$ The passage at $897 \mathrm{~b}$ is especially difficult to translate (see Mayhew, R. Plato: Laws 10, Oxford University Press. New York (2008), but my primary concern is with the claim that the soul can cleave to noûs or not. This point seems clear from the text. The difficult issue of determining whether there is meant to be a 'divine' reason seems to have no bearing on my claims here.

34 Although similar claims are made in the Timaeus (Cf. 34c \& 46c), the Timaeus stops short of attributing all transformations of the cosmos (good \& evil, beauty \& ugliness, etc.) to the soul. 
remarks in Book X suggest the following, which I will defend below: first, the thesis that no one errs willingly is inconsistent with the account of the soul as it is developed in Book X; second, the infallibility thesis, in order to remain consistent with that account, must be modified. Infallibility can be retained, but only in a conditional form.

The denial of the thesis that no one errs willingly is first suggested by the Athenian's claim about the soul's options. In the passage noted above (897ab), the Athenian says that the good soul is the one that "cleaves to reason" and the evil the one that "allies itself with unreason". The evil kind of soul, which is later, at 900e, restricted to human soul, is described as having the capacity for bringing about disorderly motions. ${ }^{35}$ Whether a human soul exercises this capacity or the capacity for bringing about orderly motions is determined by whether the soul aligns itself with reason or with unreason. This passage, though, leaves two questions unanswered. First, it is unclear whether the soul's act of aligning itself with reason or unreason is in any sense a genuine act. It is also unclear what would explain the soul's movement toward reason or unreason. In other words, does the soul have some capacity that is prior to or independent of reason, by which it can, in some sense, decide or choose? If so, what kind of capacity is this?

The full answers to these questions would require a close look at the moral psychology of the Laws as a whole. The Book X arguments alone do not give an adequate picture of the inner workings of the soul. Still, the arguments in Laws X are sufficient to show that what one wills, and then does, is not inevitably determined by what one believes or knows to be good. ${ }^{36}$ The evidence of Book X begins with the concluding sections of the arguments for the priority of soul considered above. The Athenian asserts that the soul is the cause of all things in virtue of its self-generating motion. He notes that the motions of the soul, including wish, reflection, and others are motions that can either attach themselves to

${ }^{35} \mathrm{I}$ am in agreement with Carone (2005, Ch. 8) that the evil soul is to be understood as the human soul, rather than the divine or cosmic soul.

${ }^{36}$ Bobonich (2002, 264-5) notes that the Laws on the whole upholds the thesis that akrasia is possible - that someone may know what is best and yet, without being compelled or forced in some way, fail to do what they know to be best. Bobonich notes the claim in Book III (at 689b) that the soul can oppose not just beliefs but knowledge as well. The only evidence in Book X itself comes in the Athenian's discussion of what kind of guardians the gods should be thought to be. Here (at 902ab) the Athenian notes that we should not think that the gods - like human beings - fail to do what they know to be best. 
noûs or to anoia (897a). This suggests that the human soul is free in some sense. It could take either of these two courses. This passage, however, is indeterminate on its own. It is plausible, given just this passage, that Plato here means only to say that the motions of the soul can be distinguished from their quality (intelligent or senseless) in account without claiming that the motions (and their attendant capacities) are in any sense prior. Without some further account of the inner workings of the soul's decision making, it remains unclear whether a soul's aligning itself with unreason is something that it does willingly. ${ }^{37}$

Further evidence occurs during the Athenian's argument that the gods are concerned for human beings (899d-905d). Here he sketches a system of cosmic justice according to which good and evil souls are, as the result of the god's design, located in the appropriate areas. The god is concerned only to "promote a soul with a promising character to a better situation, and relegate one that is deteriorating to an inferior, as is appropriate in each case, so that they meet the fate they deserve" (903de). The framework of cosmic justice - especially the system of penalties and rewards - is set by the cosmic soul, but it remains open to each individual to determine which course she will take. The Athenian asserts that while the rules governing the changes from better to worse situations and vice versa have been established,

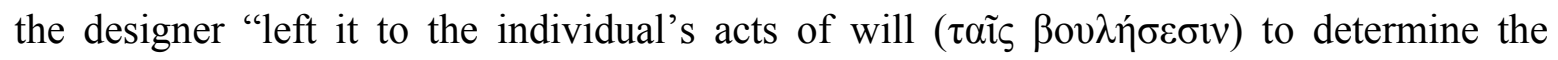
direction of these changes" (904b). Finally the Athenian reaffirms this by pointing out that

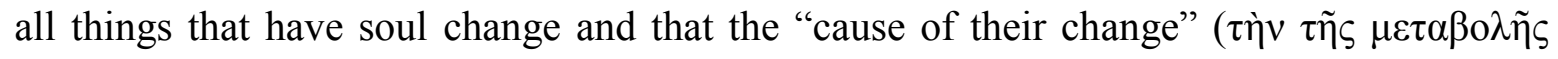

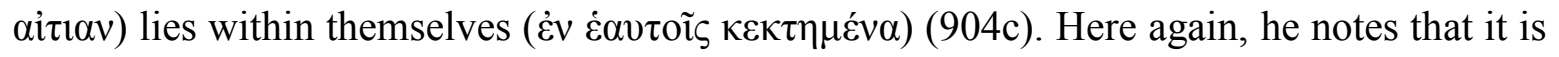

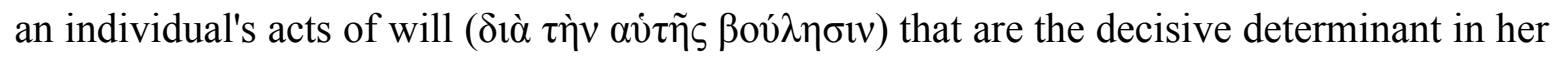
direction.

This system of reward and punishment would make little sense if it were the case that no one errs willingly. If everyone wants the good and is rewarded for just this, then the direction of change would be the same for everyone. This system, instead, seems to require a different view. The simplest explanation seems to be that Plato, in the Laws, rejects the thesis that no one errs willingly. The system of cosmic reward and punishment suggests that

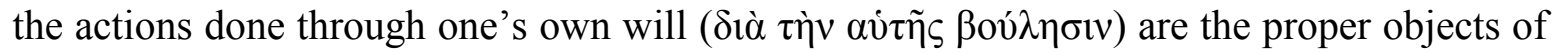
moral evaluation. The passage makes it clear that it is the quality of the acts of will

${ }^{37}$ The passage from Book III (689b) is helpful here. The soul is said to oppose knowledge, belief,

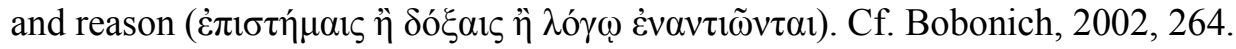


themselves (rather than an individual's understanding or ignorance of the good) that determines the direction of change.

The effect of the Athenian's argument here is that it draws a sharp distinction between the soul's capacity for choice, on the one hand, and the role that the good - even knowledge of the good - plays in framing that choice. The basis of the thesis that no one errs willingly involved the claim that the proper object of one's desire is the good. Failure to perform correct actions is explained by one's failure to have knowledge of the good, despite the fact that one wishes for it. One's fate in the system of cosmic rewards and punishments is to be determined on the basis of what one wills rather than on the basis of whether one errs in some weaker sense. But such a system presupposes that one's will is not somehow necessarily bound to what is good.

The Laws X arguments appear, then, to entail the denial of the thesis that no one errs willingly. The fate of the infallibility thesis is less clear. On the one hand, the account of the soul's choice - to side with reason or unreason - seems to be an account of choice independent of knowledge. The argument seems to require this. The soul's decision to choose noûs or annoia is the activity of one of the soul's most basic movements, whereas knowledge - it would seem - would be a feature of the soul's activity at a later stage (after, for instance, siding with reason). Thus the metaphysical picture that is sketched in the Laws X argument seems to undercut the infallibility thesis insofar as the soul's capacity for choice is independent of its knowledge. On the other hand, the way in which this picture undercuts the infallibility thesis seems to be a very technical, and possibly inconsequential, one. It seems that the question we begin with matters. If the question is whether knowledge by its presence alone guarantees correct action, then the answer appears to be 'no'. The soul's capacity for choice appears to be one that is independent of what the soul knows. This is the lesson from the passages above that show the denial of the thesis that no one errs willingly. In some cases of error, it may well be that one knows - rather than merely believes - that a course of action is not the best overall and yet may carry out the course of action anyway. Such cases would mean the denial of the infallibility thesis as well.

On the other hand, if the question is whether there are conditions under which knowledge can, by its presence, guarantee correct action, then the answer may still be 'yes'. The conditions under which this might happen would be those in which an individual has, 
through her own act of will, chosen to align with reason. In other words, a soul that has aligned itself with reason, and gained knowledge, will not err. But here something interesting has emerged about the infallibility thesis that is otherwise less clear. What makes a soul infallible is only partly that it has knowledge. Having knowledge may be a necessary component, but first a soul has to make the choice to align itself with reason. In any case, it is the choice to align with reason - and not actually getting it right - that is rewarded in the system of cosmic justice.

The status of the infallibility thesis in Laws $\mathrm{X}$ is perhaps left unsettled by the text. It seems that the arguments there either deny the thesis outright in denying that a soul that has knowledge must act correctly or they uphold a weakened, conditional, version of it. The uncertainty about the infallibility thesis is perhaps inevitable. The role knowledge plays in producing correct action is a matter that is directly related to the source of error. In the discussion of the pessimistic view in the Timaeus, it was clear that if the body is the source of error, then the claim that knowledge is an infallible guide is problematic. This problem was noted in the Phaedo and, as I have argued, shown in the Timaeus to be intractable. The discussion here of the optimistic view and the Laws' claim that the soul is the cause of evil faces a similar difficulty. If the soul is the ultimate cause of error, then the claim that knowledge is an infallible guide to right action is susceptible to counter-examples, which Plato seems to accept as genuine. ${ }^{38}$ On the other hand, Plato seems - if we accept the conditional version of the infallibility thesis - to remain committed to the idea that knowledge can guarantee correct action only if one is properly motivated in ways that go beyond one's knowledge of the good. ${ }^{39}$

${ }^{38}$ Cf. Laws 902ab, 875ac.

${ }^{39}$ Bobonich (2002) notes that in both the Republic and Laws, Plato recognizes a distinction between the strength of a person's desire to do X, on the one hand, and one's evaluation of X, on the other (cf. 265). This contrast, though not drawn explicitly in Book $X$, is helpful in illuminating the distinction that I have relied on here between one's capacity for choice (boulêsis) and what one knows. To say that the infallibility thesis is upheld in conditional form is to say that if one's desire to do $\mathrm{X}$ is through whatever means - sufficiently strong, then one's evaluation - or one's knowledge - that X is best overall will guarantee correct action. 


\section{Conclusion}

My primary aim here has been to draw attention to the two ways of thinking about the body that appear in Plato's dialogues and to show that the choice between these two is not simple or straightforward, given the relations these views bear to other claims that Plato advances. I began by noting that the two views of the body present a dilemma. On the one hand, Plato is quite concerned to steer us away from concern for material goods, including excessive attachment to the goods of the body. On the other hand, Plato wishes to uphold the view that proper training of one's soul will enable one to act rightly and thus live well. The pessimistic view appears to go too far in aiding the first goal. To justify the effort to escape the body, Plato vilifies the body to such an extent that it is unclear whether training in philosophy will be sufficient to overcome its influence. The optimistic view, however, threatens something else. If the body is not evil or the original cause of evil, then some other account is needed of the origin of evil. The account presented in the Laws avoids the problem posed by the pessimistic view of the body, but in doing so it places the responsibility for evil more squarely with the agent. This, in turn, calls into question the justification of Plato's views about the authority of knowledge and the otherwise purported causes of human error.

It is my view that this dilemma is unresolved in the dialogues, though I hope that the investigation here shows that Plato, at the very least in his writing of the Timaeus and Laws, is increasingly aware of the consequences of affirming each of the two views of the body. Perhaps one might resolve the dilemma by defending one or another thesis about the place of these dialogues in Plato's thinking overall. The most plausible such thesis, to my mind, might claim that the view in the Laws should be taken as the final verdict on the choice between optimism and pessimism. This thesis would thus tell us which horn of the dilemma Plato favors, and would thus tell us about how Plato ultimately resolves the ambiguity about the status of the body that runs through the dialogues. I want to suggest, however, that for this view a different, but I think closely related dilemma lurks in the pages of the Laws.

The ambiguity about the role and status of the body running through the dialogues is, it seems, mirrored by a related ambiguity in the Laws, where responsibility for evil is more squarely assigned to the soul. The ambiguity about the body enables Plato to both criticize and demonize the body while also upholding the importance of having a well-balanced and 
well-trained body. It seems that something like this ambiguity about the mind and the role that knowledge plays in producing correct action pervades the Laws. It has spawned scholarly disagreements about the role, for example, of persuasion in the Laws, and the relation between virtue and obedience to the laws. On the one hand, the system of laws (together with their preambles) in the dialogue seems designed to cultivate virtue and understanding in the citizens. ${ }^{40}$ On the other hand, the Athenian has seemed to some readers to be somewhat cavalier about the quality of arguments that are put forward and at the same time pessimistic about the ability of the audience (including, especially, Cleinias) to follow difficult argument. ${ }^{41}$ These are increasingly well-known difficulties with the interpretation of the Laws. My claim here is that both interpretations gain some traction because Plato is unclear about the role of knowledge in producing correct action. Though he nowhere in the dialogue denies that knowledge is important or necessary, the implication of the argument in Book X, and perhaps claims elsewhere in the Laws, is that knowledge alone is insufficient. Thus it becomes unclear whether Plato aims for the preambles to the laws to produce knowledge through rational persuasion or to secure agreement through non-rational means.

The view that has emerged here suggests first that Plato may well intend both. Knowledge is important but can only be a reliable guide to correct action if those who have knowledge are properly motivated. But it is important as well, and more urgent, that citizens take on the right motivations in the absence of knowledge.

Perhaps something similar can be said, in the end, concerning Plato's statements about the body. Those statements that confirm or suggest the pessimistic view as a way of thinking about the body give the impression that the body is to be scorned or rejected - that the body is something from which one would best escape. On the other hand, those passages that confirm or suggest the optimistic view give the impression that there are appropriate ways to care for the body - a proper diet, a proper amount of exercise - and that one should attend to these accordingly. The ethical message that pervades both might be that it is best not to stake one's well-being on the interests of the body. In more urgent contexts, the call away from the body is given more force (sc., 'escape'), but the general ethical point is that one should not

${ }^{40}$ Cf. Annas, 'Virtue and Law in Plato' in Bobonich (2010), Bobonich, "Persuasion, Compulsion and Freedom in Plato's Laws. Classical Quarterly 41 1991, 365-388.

${ }^{41}$ Cf. Mayhew, 'Persuasion and Compulsion in Plato's Laws' Polis. $(24,1)$ 2007, 91-111. 
devote too much attention to the body. Proper attention to the body will be whatever produces order.

While the ethical message is relatively clear at this level of generalization, the metaphysics that underlies the statements about the body cannot be made to agree in this way. The two clearest metaphysical views of the body lead not to a higher level generalization about how to treat the body, but to a choice about the ultimate cause of human error (and evil generally). That choice, I have argued, has implications both for ethics and for what role knowledge can have in guiding action.

Robert Wagoner

University of Wisconsin Oshkosh

\section{Bibliography}

Bobonich, Christopher. 1991. "Persuasion, Compulsion and Freedom in Plato's Laws." The Classical Quarterly, New Series 41 (2): 365-88. https://doi.org/10.1017/s0009838800004547

Bobonich, Christopher. 2002. Plato's Utopia Recast: His Later Ethics and Politics. New York: Oxford University Press. https://doi.org/10.1093/0199251436.001.0001

Bobonich, Christopher. 2010. Plato's Laws: A Critical Guide. Cambridge Critical Guides. New York: Cambridge University Press. https://doi.org/10.1017/cbo9780511781483

Carone, Gabriela. 2005. Plato's Cosmology and Its Ethical Dimensions. Cambridge: Cambridge University Press. https://doi.org/10.1017/CBO9780511734915

Cherniss, Harold. 1954. "The Sources of Evil According to Plato." Proceedings of the American Philosophical Society 98 (1): 23-30.

Cooper, John (ed.). 1997. Plato: Complete Works. Indianapolis: Hackett Publishing.

Gill, Christopher. 2000. “The Body's Fault? Plato's Timaeus on Psychic Illness.” In Reason and Necessity: Essays on Plato's Timaeus, 59-84. Oakville, CT: Duckworth.

Johanson, Thomas Kjeller. 2004. Plato's Natural Philosophy: A Study of the Timaeus-Critias. New York: Cambridge University Press. https://doi.org/10.1017/CBO9780511518478

Kamtekar, Rachana. 2010. "Psychology and the Inculcation of Virtue in Plato's Laws." In Bobonich, 2010. https://doi.org/10.1017/CBO9780511781483.008

Mackenzie, Mary Margaret. 1981. Plato On Punishment. Los Angeles: University of California Press.

Mayhew, Robert. 2007. "Persuasion and Compulsion in Plato's Laws 10." POLIS 24 (1): 91-111. https://doi.org/10.1163/20512996-90000109

Mayhew, Robert. 2008. Plato: Laws 10. New York: Oxford University Press. https:// doi.org/10.1093/actrade/9780199225965.book.1 
Nightingale, Andrea. 1996. "Plato on the Origins of Evil: The Statesman Myth Reconsidered". Ancient Philosophy 16: 65-91. DOI: 10.5840/ancientphil199616112

Saunders, Trevor J. (trans.). 1997. Laws in Cooper, 1997.

Segvic, Heda. 2000. "No One Errs Willingly: The Meaning of Socratic Intellectualism". Oxford Studies in Ancient Philosophy XIX: 1-46.

Vlastos, Gregory. 1939. "The Disorderly Motion in the Timaios." The Classical Quarterly 33 (2): 71-83. https://doi.org/10.1017/s0009838800020966

Wood, James L. 2009. "Is there an ARCHÊ KAKOU in Plato?" The Review of Metaphysics 250 (Dec.): 349-384.

Zehl, D. J. (trans.). 2000. Plato: Timaeus, Indianapolis and Cambridge, Mass: Hackett Publishing Co. 